\title{
REFLEXÕES SOBRE A TEORIA E A PRÁTICA EM UM CURSO DE PEDAGOGIA
}

Fátima Kzam Lacerda | fatima_kzam@yahoo.com.br

Professora Assistente do Departamento de Processos Bioquímicos do Instituto de Química da UERJ, Diretor de Pólo de Apoio presencial do CEDERJ/UAB, Doutoranda do Programa Multidisciplinar em Meio Ambiente da UERJ (PPGMA).

Luiz Fernando Perez Moraes | pereznf@yahoo.com.br

Tutor presencial no Curso de Licenciatura em Pedagogia no CEDERJ, pós-graduado em Psicopedagogia Institucional e Planejamento, Implementação e Gestão de EAD / UFF.

Cristina Rodrigues Abrahão |

Pedagoga atuando no Município de Nova Friburgo, Tutora Presencial do Curso de Licenciatura em Pedagogia no CEDERJ/UAB, pós graduada em Psicopedagogia Clínico-Institucional - Faculdade de Filosofia Santa Doroteia, em Planejamento, Implementação e Gestão de EAD / UFF.

Maria Cristina Bessa Lippmann | cristina.iprj@gmail.com

Economista do Instituto Politécnico da UERJ, Advogada da Comissão da Escola Superior dos Advogados/OAB, pós graduada em Planejamento, implementação e gestão de EAD/UFF, em Planejamento e gestão de Recursos Humanos PUC/RJ, em Direito Civil

Constitucional - UERJ, em Direito e Processo do Trabalho VRB/OAB.

\section{Resumo}

Este trabalho tem como objetivo geral analisar o curso de Pedagogia para as séries iniciais oferecido na modalidade semipresencial em um polo de apoio presencial situado na região serrana do Estado do Rio de Janeiro no que se refere ao processo de avaliação e suas implicações. São analisados o projeto pedagógico do curso, as ferramentas de avaliação, o sistema de tutoria presencial e os resultados externos utilizando pesquisas bibliográfica e de campo. Verificou-se a necessidade de que o projeto político-pedagógico seja mais conhecido, vivenciado e discutido pelos diferentes sujeitos/atores da educação a distância. Nessa perspectiva, espera-se contribuir para o aprofundamento da reflexão e consequente aperfeiçoamento do processo avaliativo da aprendizagem e institucional.

\section{Palavras-chave}

Educação a distância.

Avaliação da aprendizagem.

Projeto político-pedagógico. Tutoria. Avaliação institucional. 


\section{Evaluation in distance education: reflections on theory and practice in a Pedagogy course}

\section{Abstract}

This paper aims at analyzing the Pedagogy course for the early grades offered in a semi-distance modality in a polo located in the mountainous region of Rio de Janeiro with regard to the evaluation process and its implications. A study of the political-pedagogic project of the course, the assessment tools, the system of mentoring and the external results was realized using literature searches and field. There is a need for the political-pedagogic project to be best known, experienced and discussed by the different subjects/actors of distance education. In this perspective, it is expected to contribute to the deepening of reflection and consequent improvement of the learning evaluation process and institutional.

\section{Keywords}

Distance education. Learning evaluation. Politicalpedagogical project. Mentoring system. Institutional evaluation.

\section{Introdução}

Desde que os primeiros educadores jesuítas chegaram ao Brasil e implantaram um sistema de educação formal até aos dias atuais, muitos avanços e retrocessos podem ser observados na busca por uma identidade cultural e por uma educação de qualidade e inclusiva. Assim, inúmeras possibilidades e projetos de cursos presenciais e a distância têm sido implementados, tanto pelos governos federal, estadual e municipal quanto pelas iniciativas privada, comunitária e organizações não governamentais.

Nesse cenário, na área da educação a distância (EAD), o CEDERJ (Centro de Educação Superior a Distância do Estado do Rio de Janeiro), um consórcio formado pelas seis universidades públicas do Estado (UFF, UNIRIO, UFRJ, UFRRJ, UERJ e UENF) apresenta-se como uma importante possibilidade de inclusão social (BIELSCHOWSKY et al, 2003). Atuando desde 2001, seus principais objetivos são contribuir para a interiorização do ensino superior público, gratuito e de qualidade; facilitar o acesso àqueles que não podem estudar no horário tradicio- nal; atuar na formação continuada dos professores e aumentar a oferta de vagas em cursos de graduação e pós-graduação nas modalidades a distância e semipresencial.

O Ministério da Educação, por meio da Secretaria de Educação a Distância, elaborou em agosto de 2007, os Referenciais de Qualidade para a Educação Superior a Distância, no intuito de oferecer elementos para reflexão e nortear as discussões $e$ debates sobre essa modalidade de ensino. Esses referenciais envolvem aspectos pedagógicos, recursos humanos e de infraestrutura. Desse modo, conforme o documento supracitado, alguns aspectos devem estar integralmente expressos no projeto político-pedagógico de um curso nessa modalidade, dos quais, para o âmbito desta pesquisa, são analisadas apenas algumas dimensões entre as elencadas a seguir:

(i) Concepção de educação e currículo no processo de ensino e aprendizagem; (ii) Sistemas de comunicação; (iii) Material didático; (iv) Avaliação; (v) Equipe multidisciplinar; (vi) Infraestrutura de apoio; (vii) Gestão acadêmico-administrativa; (viii) Sustentabilidade financeira (BRASIL, 2007, p. 7).

Os desafios atuais refletem, nesse processo de crescimento contínuo, visões qualitativas, nas quais um sistema de educação a distância apresente indicadores para a avaliação e possibilite a melhoria da qualidade do ensino na graduação. Outro fator importante é o autoconhecimento da instituição sobre a EAD em busca da melhor adequação ao cumprimento de suas funções, visando a garantir um padrão de excelência nos cursos.

Nesse aspecto, a Educação a Distância é um assunto polêmico e, mesmo no âmbito da universidade, não existe consenso sobre suas possibilidades, alcances e limitações. Ao entrelaçar as temáticas da EAD e da avaliação, verifica-se que vários questionamentos ainda pairam no ar, o que certamente exigirá que muitas pesquisas sejam realizadas por aqueles grupos que se dedicam a essas duas áreas.

A metodologia adotada neste trabalho realizou-se a partir de abordagens qualitativa e quantitativa, utilizando pesquisas bibliográficas e de campo, 
além de análise documental, tomando como referência o curso de Pedagogia para as séries iniciais oferecido no Polo de Apoio Presencial de Nova Friburgo. Foram investigados o projeto político-pedagógico do curso, os instrumentos de avaliação disponíveis (material impresso, avaliações a distância (ADs) e presenciais (APs)), o sistema de tutoria presencial e os resultados externos obtidos pelos estudantes, tendo como sujeitos da pesquisa os coordenadores de curso e disciplina, tutores e alunos, no período de agosto de 2003 a maio de 2010.

\section{A avaliação da aprendizagem e a EAD}

Ao longo da história da Educação, várias questões têm sido objeto de discussão, com a finalidade de aprofundar o conhecimento, aperfeiçoar as práticas pedagógicas e, assim, aprimorar a qualidade do ensino e da aprendizagem. Desse modo, desde os seus fundamentos e princípios norteadores até aos aspectos didático-metodológicos, tudo tem sido incluído nos debates.

Nessa dinâmica, como assinala Freire (1996), em que a reflexão sobre a teoria/prática se encontra dialeticamente, uma questão especial tem sido enfatizada: o processo de avaliação e sua complexidade. Avaliar, portanto, é sempre um desafio em todas as modalidades de educação. Podemos destacar quatro diferentes formatos de avaliação: avaliação de desempenho, avaliação de aprendizagem, avaliação de programas e projetos e avaliação institucional.

Quando se trata da avaliação da aprendizagem em cursos a distância e semipresenciais - especialmente em um curso de Pedagogia - não se tem ainda conhecimento de pesquisas oficiais que comprovem a eficácia dos instrumentos utilizados no processo, tanto na formação quanto na prática pedagógica dos profissionais de Educação graduados nessa modalidade. No entanto, a dinâmica da avaliação da aprendizagem e dos referenciais teóricos utilizados pela instituição para fundamentar a sua prática pedagógica configura-se com as mesmas dificuldades e complexidades do ensino presencial.

Nesse sentido, ao se pensar em um curso para formação de professores que consiga articular o ensino e a pesquisa, a teoria e a prática, este precisa estar comprometido com uma proposta curricular e com uma avaliação que garantam essa vivência durante todo o curso. Para isso, o projeto político-pedagógico, ao enumerar alguns princípios que visem à apropriação de algumas habilidades, evidencia essa preocupação, quando propõe a "articulação da teoria e da prática no percurso curricular, com predominância da formação sobre a informação e contemplando a indissociabilidade e a complementaridade entre ensino, pesquisa e extensão" (CEDERJ, 2000, p. 10). Logo, a avaliação e a proposta pedagógica precisam estar em consonância com esse objetivo, tendo os atores da EAD - gestores, professores, coordenadores - a tarefa de propor ações que priorizem o alcance dessas habilidades.

Em referência à avaliação da aprendizagem em EAD, segundo Bentes:

a avaliação pode ser entendida como um processo que permite a coleta e a análise de informação relevante para apoiar juízos de valor sobre o objeto avaliado. Eles serão utilizados para redirecionar, se necessário, as situações que puderem ser melhoradas e para uma posterior tomada de decisões sobre qualificação e certificação (BENTES, 2009, p. 167).

Observa-se a importância da avaliação para a Educação e, na educação a distância especialmente, quando os referenciais teóricos/práticos estão se delineando, em processo de construção colaborativa. Nesse sentido, parece essencial verificar se os aspectos teóricos apontados por Bielschowsky (2003) ao referir-se à proposta de avaliação no CEDERJ encontram ressonância na prática ou se precisam ser revistos:

A avaliação de cada disciplina é parte integrante do processo ensino/aprendizagem e pode variar em função das orientações dos professores responsáveis pela disciplina ou de necessidades contextuais vigentes no momento da implantação. O processo avaliativo de uma disciplina é composto por exercícios avaliativos que não contam pontos para a média do aluno na disciplina, duas avaliações semestrais compostas de 
uma parte a distância (20\% da nota) e uma parte presencial (80\% da nota) e, quando necessário, uma avaliação suplementar presencial (BIELSCHOWSKY, 2003, p. 2).

Percebe-se que parte do problema concentra-se, aparentemente, na valoração dos diferentes instrumentos avaliativos, na sua intencionalidade e no seu grau de dificuldade. E complementa o autor supramencionado:

A interatividade dos alunos entre si e com os tutores é fortemente estimulada na realização dos exercícios avaliativos, visando a implementar um processo de ensino/aprendizagem de sucesso. Nos polos regionais é permanente o incentivo aos alunos para o trabalho em grupo e para a utilização da internet na interação com os tutores a distância (BIELSCHOWSKY, 2003, p. 2).

Entretanto, se os aspectos mencionados - interação com os tutores, exercícios avaliativos e trabalhos em grupo - são parte integrante do processo da avaliação formativa que se pretende - com sucesso, como eles são avaliados? Quando são avaliados? Quem os avalia? Como destaca Bielschowsky (2006),

tanto na educação a distância quanto na presencial, é preciso, antes de mais nada, criar uma cultura de avaliação permanente que permita que os atores da instituição, alunos, docentes e servidores técnico-administrativos, discutam os diversos aspectos relacionados ao processo de ensino/aprendizagem, e não apenas aqueles em que ele atua diretamente (BIELSCHOWSKY, 2006, p. 57).

Portanto, se as questões pertinentes à formação dos professores no ensino presencial sempre foram alvo de debates, de controvérsias didático-metodológicas e de exigências para uma formação continuada de pesquisadores, elas são ainda mais exigentes e acentuadas na formação que se realiza na modalidade a distância ou semipresencial.

Assim, pretende-se, com este estudo, contribuir para ampliar a reflexão e os debates acerca do processo avaliativo na EAD, especialmente em um curso de Pedagogia, visto que a qualidade da formação de professores tem reflexo direto na qualidade do processo de ensino/aprendizagem e, portanto, na educação.

\section{O projeto político-pedagógico}

A construção de um projeto político-pedagógico se traduz numa tarefa que precisa considerar o contexto sociocultural dos sujeitos envolvidos, tendo a participação como elemento facilitador para tal construção. Acrescentam-se a isso as etapas essenciais para a sua organização que, além de evidenciar a filosofia de ensino adotada pelo grupo, articula-se com as diretrizes da educação nacional e com a realidade na qual a instituição está inserida. Veiga (1995) conceitua projeto político-pedagógico como:

um instrumento de trabalho que mostra o que vai ser feito, quando, de que maneira, por quem, para chegar a que resultados. Além disso, explicita uma filosofia e harmoniza as diretrizes da educação nacional com a realidade [...] traduzindo sua autonomia e definindo seu compromisso com a clientela. É a valorização da identidade [...] e um chamamento à responsabilidade dos agentes com as racionalidades interna e externa. Essa ideia implica a necessidade de uma relação contratual, isto é, o projeto deve ser aceito por todos os envolvidos, daí a importância de que seja elaborado participativa e democraticamente (VEIGA, 1995, p. 110).

Esse compromisso se estabelece numa relação dinâmica, na qual a discussão, a reflexão, a mudança, a aquisição de novas perspectivas possibilitam aos envolvidos buscar cada vez mais conhecer. Dessa forma, as etapas de elaboração do projeto, segundo Veiga (1995) trazem como ponto de partida a análise da situação, que requer o conhecimento sobre alunos, equipe pedagógica, levantamento de informações sobre as condições materiais e financeiras da instituição e sobre a possibilidade de trabalhar com a comunidade. A definição de objetivos propõe a discussão sobre a função da instituição e de seu compromisso social. Outra importante etapa é a escolha das estratégias que organizam o levantamento de aspectos que precisam ser melhorados com base na ação do grupo ou através de ações que dependem de apoio externo.

Enfatiza-se que a etapa que define a ação pedagógica é a coordenação entre os diversos profissionais que discutem, definem e zelam por estratégias que visam garantir a aprendizagem dos alunos. Acrescenta-se, ainda, a implementação e, por último, o acompanhamento e a avaliação, que não se limitam a constatar 
situações, $e$ sim a estimular ações que visem a corrigir e aprimorar o projeto.

Por esse motivo, o projeto não é apenas um registro formal, no qual os objetivos traçados ficam arquivados. Logo, aponta-se para a necessidade de este ser vivenciado pelos sujeitos envolvidos no processo educativo da instituição.

\subsection{Considerações sobre o projeto político- pedagógico do curso de Pedagogia}

O projeto político-pedagógico (PPP) do curso em questão apresenta em seu texto seus objetivos e destaca a preocupação em oferecer um ensino superior de qualidade. Para garantir essa qualidade, o documento enfatiza que os alunos são "construtores de conhecimento, participantes ativos de um processo organizado e sistêmico" (CEDERJ, 2000, p. 9). Isso possibilita a compreensão de que, para os alunos serem construtores do conhecimento, as ações pedagógicas devem propor atividades que lhes possibilitem vivenciar gradativamente essa conquista.

Dessa maneira, segundo o PPP, o desenvolvimento dos cursos segue alguns princípios que se referem ao

planejamento das ações pedagógicas e tecnológicas, considerando as necessidades de aprendizagem, o perfil cultural dos alunos [...], estruturação de cada curso com base em um projeto pedagógico que direcione a elaboração e execução do currículo a partir das discussões coletivas [...], elaboração de currículos, segundo o perfil que se deseja para o aluno, considerando uma metodologia de ensino que privilegie a atitude de pesquisa como princípio educativo (CEDERJ, 2000, p. 10).

Nesse contexto, a metodologia de ensino defendida pelos princípios destacados acima é a que promove a aprendizagem ativa, na qual o aluno se desenvolve de forma autônoma. Assim, o desenvolvimento dessa autonomia se processa a partir da interação dos alunos com os professores, alunos com alunos, através de tecnologias apropriadas, no caso específico a Plataforma CEDERJ. Pontua-se ainda que a plataforma conta com ferramentas que incluem multimeios, videoconferências, supervisão acadêmica, biblioteca, recursos audiovisuais, sala de tutoria, fórum e outros.

Outro elemento importante para garantir a interação aluno/professor é a tutoria presencial. Ao tutor presencial configura-se a responsabilidade de orientar os alunos, motivando-os e encorajando-os para o estudo.

No que tange ao processo de avaliação, o PPP sinaliza para a "manutenção de processos de avaliação contínua, considerando o desempenho dos alunos $e$ a ação pedagógica, com vistas ao constante aperfeiçoamento do currículo" (CEDERJ, 2000, p. 10). Para isso, a avaliação idealizada no documento precisa ter claro que tanto a aprovação quanto a reprovação não contribuem para a construção do conhecimento. Ao contrário, o que ela promove é o distanciamento ou o abandono do ato de conhecer, resumindo-se ao mero estudo para alcançar a aprovação ou a reprovação.

Nesse contexto, a avaliação precisa levar em conta o percurso do aluno, de modo que professor e tutor levantem informações sobre os avanços, dificuldades e assim apresentem ações que possam contribuir para a superação, promovendo dessa forma a aprendizagem.

Segundo Luckesi, (2003) a avaliação

será autoritária, estando a serviço de uma pedagogia conservadora e, querendo estar atenta à transformação, terá de ser democrática e a serviço de uma pedagogia que esteja preocupada com a transformação da sociedade a favor do ser humano, de todos os seres humanos, igualmente (LUCKESI, 2003, p. 32).

Dessa maneira, o autor pontua que não basta reconhecer que é necessário adotar outra pedagogia, tampouco mudar a avaliação; é preciso reconhecer que a "teoria e a prática" precisam estar em sintonia (CEDERJ, 2000).

Conforme já descrito, o documento enfatiza que deverão prevalecer as avaliações presenciais sobre outras formas de avaliação. Para isso, essas avaliações devem ser organizadas de modo a promover aprendizagens e, mesmo, propor momentos de estudo. Precisam estar comprometidas com a proposta do curso, apresentando estreita relação com o material didático, bem como ser elaboradas para atender a esse fim. O referido documento apresenta, ainda, a fundamentação teórica do curso, que se preocupa em promover a aprendizagem significativa, além de oportunizar situações desafiadoras que contribuam para o desenvolvimento cognitivo. 
Diante dessa proposta, é imprescindível considerar (como ocorre no curso presencial) que na modalidade EAD existem alunos que apresentam dificuldades para aprender, bem como apresentam baixo rendimento. Para entender como as questões sobre a superação de dificuldades de aprendizagem são vivenciadas na prática, elaborou-se um questionário, que foi enviado por meio eletrônico para 42 coordenadores de disciplinas do curso de Pedagogia para as Séries Iniciais do Ensino Fundamental que atuam ou atuaram no Polo de Apoio Presencial de Nova Friburgo. As perguntas do questionário versavam sobre o conhecimento do PPP e a sistematização do trabalho visando a atender alunos com dificuldades de aprendizagem bem como sobre a capacitação dos tutores; mas só obtivemos resposta de seis coordenadores. As respostas obtidas apontam para o fato de que nem todos os envolvidos conhecem o documento proposto e adotam estratégias distintas, que aparentemente não são compartilhadas por todo o grupo, o que denota fragmentação nas ações pedagógicas (AUTOR 1, 2010).

Enfatiza-se ainda que, se o projeto político-pedagógico não é conhecido, considerado, vivido, modificado, discutido, torna-se um registro formal, sem valor. $\mathrm{Na}$ presente pesquisa, consideramos que a baixa participação dos coordenadores deveu-se provavelmente à dificuldade de vivenciar a avaliação como um processo de autoconhecimento e melhoria da qualidade do fazer universitário, e não como instrumento de poder e controle.

\section{As ferramentas de avaliação}

Ao longo da história da educação, a avaliação da aprendizagem, com todas as suas implicações, gerou inúmeros debates e discussões para a prática pedagógica. Muitos, inclusive, têm contribuído para o aprofundamento das reflexões, das formas e para a busca de novos modelos, frente às exigências contemporâneas, sobretudo no que se refere à utilização dos recursos que as novas tecnologias da informação e da comunicação oferecem para dinamizar o processo avaliativo no cotidiano escolar, suas possibilidades e seus limites.

Acredita-se que a dificuldade é transformar as referências conceituais para uma avaliação diagnóstica, formativa e contínua - que a maioria das instituições propõe - em ações que ultrapassem resultados unicamente somativos e classificatórios, principalmente no que se refere ao permanente acompanhamento dos estudantes, como é proposto pelos Referenciais de Qualidade para a Educação Superior a Distância:

na educação a distância, o modelo de avaliação da aprendizagem deve ajudar o estudante a desenvolver graus mais complexos de competências cognitivas, habilidades e atitudes, possibilitando-lhe alcançar os objetivos propostos. Para tanto, esta avaliação deve comportar um processo contínuo, para verificar constantemente o progresso dos estudantes e estimulá-los a serem ativos na construção do conhecimento. Desse modo, devem ser articulados mecanismos que promovam o permanente acompanhamento dos estudantes, no intuito de identificar eventuais dificuldades na aprendizagem e saná-las ainda durante o processo de ensino-aprendizagem (BRASIL, 2007, p. 16).

Nessa perspectiva, articular os mecanismos de permanente acompanhamento constitui-se no desafio atual, pois tal proposta exige a efetivação do trabalho cooperativo, sem o qual a fragmentação e a consequente superficialidade do processo avaliativo são inevitáveis. Sendo assim, as duas dimensões da avaliação que, segundo Brasil (2007), devem estar contempladas em um projeto de educação a distância - a institucional e de aprendizagem - estão imbricadas, de modo que as falhas em uma refletem em lacunas na outra. Assim, parece fundamental modificar a abordagem, a maneira de condução do processo e, como destaca Moran, a forma de organizar os princípios e os recursos tecnológicos mais adequados:

Preocupa-me ver em cursos a distância, principalmente os massivos, que utilizam provas de múltipla escolha, presencialmente, porque o MEC exige avaliações presenciais em cursos a distância. O MEC exige avaliações presenciais, o que não significa que sejam necessariamente provas nem que todo o processo de avaliação esteja concentrado só nos momentos presenciais. Ainda predomina o foco no conteúdo na maior parte dos cursos a distância e também nos presenciais. Como consequência, a avaliação se concentra na verificação da apreensão desse conteúdo e esquece todas 
as outras dimensões: as de processo, de construção coletiva do conhecimento, das dimensões emocionais e éticas do projeto de ensino e aprendizagem, da flexibilidade na adaptação ao ritmo do aluno (MORAN, 2006, s/p, grifo nosso).

Desse modo, adequar todos os elementos mencionados pelo autor à realidade dos alunos que buscam cursos a distância exige inicialmente dos atores envolvidos - coordenação, tutores e alunos - o entendimento comum do que seja essa modalidade de ensino, quais são as suas exigências, a necessidade de redimensionar o tempo real em virtual e de construir as obrigações $e$ responsabilidades éticas. São tarefas que supõem um planejamento estruturado - objetivos, conteúdos e metodologia - e em constante reavaliação.

E ainda, conforme destaca Gusso, ao planejar as atividades, o professor deve ter em mente como questões norteadoras da sua ação pedagógica: "Para quem $e$ para que planejar? Por que planejar? Qual o objetivo do planejamento? Quais metodologias são adequadas ao formato do curso? Como avaliar os resultados?" (GUSSO, 2010, p. 6). Desse modo, essas indagações iniciais o remeteriam a outras mais específicas, como no caso do planejamento do material didático impresso e na verificação da sua utilização pelos(as) alunos(as): Quem são os alunos? Eles utilizam esse instrumento? Como? Que experiências têm com ele e em quais circunstâncias? Fazem as tarefas propostas? Compartilham os resultados nas tutorias? Enfim, são questões que apontam para a busca de uma avaliação significativa.

Sabe-se que o processo de avaliação em cursos a distância, ainda que bastante complexo, é o eixo fundamental para a sua efetivação. E, quando bem delineado, em uma dinâmica que contemple uma reflexão contínua, tende a aprimorar suas ações na perspectiva do desenvolvimento do aluno.

Embora se saiba que existem entraves internos $e$ externos às instituições que implementam cursos de educação a distância e que precisam ser dissolvidos, por exemplo, quanto à legitimação, à credibilidade, à competência profissional dos formandos e aos preconceitos, a avaliação é, sem dúvida alguma, o fator que, sendo fundamental no processo da EAD, contribuirá para a dissolução dos entraves ao seu processo.

\subsection{A Avaliação no curso semipresencial de Pedagogia}

Considerando que a avaliação é um processo, pode-se inferir que os instrumentos avaliativos - módulos, avaliações a distância e presenciais -, apesar das suas peculiaridades, deveriam ser igualmente importantes em um curso semipresencial centrado no estudante e na sua aprendizagem. Percebe-se que no curso de Pedagogia existe uma preocupação em integrar os diferentes instrumentos, tais como: exames e tarefas e, aparentemente, não se deveria destacar nenhum em especial, conforme as indicações contidas no projeto político-pedagógico.

Porém, a experiência do ensino no modelo presencial sinaliza que, para articular diferentes instrumentos avaliativos em um processo que assegure a aprendizagem significativa, é fundamental que os gestores reavaliem constantemente o percurso, o que nem sempre é realizado. $\mathrm{E}$, na $\mathrm{EAD}$, isso também se apresenta como um desafio acentuado, já que as relações entre os atores envolvidos acontecem sob outro paradigma.

Nesse contexto, articular uma avaliação contínua e o acompanhamento permanente dos estudantes, como propõe Brasil (2007), torna-se um desafio no curso semipresencial de Pedagogia, pois a equipe - coordenadores de disciplina, tutores a distância e presenciais - devem estabelecer uma comunicação intensa, condição para identificar as dificuldades de toda ordem $e$ para buscar as soluções possíveis durante o processo, o que é especialmente difícil.

Os instrumentos avaliativos analisados neste trabalho compõem-se do material impresso, isto é, dos módulos com os conteúdos sistematizados das disciplinas do curso; das avaliações a distância e presenciais. Para realizar essa análise, elaborou-se um questionário com o intuito de conhecer a percepção dos estudantes acerca da utilização desses instrumentos do processo avaliativo. Foram recolhidas as respostas de 62 alunos e ex-alunos do Polo de Apoio Presencial de Nova Friburgo.

Foi possível verificar que, apesar do emprego de inúmeros recursos materiais e humanos para a elaboração de um material impresso de qualidade, este é subuti- 
lizado pelos alunos, já que um número expressivo de participantes declarou utilizá-lo somente como apoio antes das provas. Percebeu-se ainda, uma distorção na compreensão dos(as) estudantes sobre as exigências de uma graduação na modalidade EAD quanto ao tempo disponível e à disciplina para estudo, fundamentais para um bom desempenho acadêmico (AUTOR 2, 2010). Desse modo, parece prevalecer a repetição da cultura da prova - com tudo que isso indica. Em outras palavras: os resultaram apontaram que grande parte dos estudantes está construindo uma visão equivocada do que seja o processo avaliativo e da avaliação, sobretudo daquela idealizada pela instituição como formativa, que estimula o estudo e a pesquisa. E, com isso, direcionam o foco da vida acadêmica apenas para a certificação.

\section{O sistema de tutoria na EAD}

Conforme apontam Medeiros e colaboradores (2007), a tutoria é vital para um curso de qualidade em $\mathrm{EAD}$, pois ela estimula os estudantes a superar dificuldades e limites. Entretanto, os modelos de tutoria diferem em cada instituição, como também o entendimento do que seria um tutor na EAD. Para Bentes (2009), por exemplo, o tutor é aquele que alimenta com conteúdo didático o aluno e faz o trabalho de inseri-lo e mantê-lo no processo de ensino-aprendizagem. $\mathrm{O}$ autor ressalta que, para atingir esse objetivo, o tutor precisa conhecer o perfil do aluno de EAD. Precisa também dominar novas habilidades, como utilizar novos esquemas mentais para criar uma nova cultura indagadora e plena em procedimentos de criatividade e ter disponibilidade de intervir, com o objetivo de construir o conhecimento com o aluno de maneira integrada e participativa.

Santos (2002) discorre sobre o sentido etimológico da palavra tutor (protetor, defensor). Para a autora, o termo não contempla a complexidade do novo papel e da função exigida para esse profissional da EAD; ela o compara ao conceito etimológico da palavra professor, que é aquele que ensina uma arte, ciência, técnica ou disciplina. Para Santos (2002), o professor do ciberespaço incorpora o papel de interlocutor, uma vez que vai mediar o processo que conduzirá o aluno a ser sujeito de sua própria aprendizagem. Os papéis diferem, mas ambos fazem parte de uma modalidade de educação em que as novas tecnologias de comunicação permitem novas formas possíveis de ensinar $e$ aprender. A linguagem precisa ser coerente com o espaço de comunicação onde acontece a aprendizagem e que potencialmente conduz à interatividade. Essa nova forma diferencia-se daquela em que o professor/ tutor trabalhava conteúdos estáticos, de forma unidirecional para o estudante - que era um ouvinte, ou seja, apenas um receptor de informações e conteúdos. $\mathrm{Na}$ $\mathrm{EAD}$, conforme apontado por Saraiva e colaboradores (2006), todos são partícipes da construção de comunidades que aprendem em conjunto, trocam de papéis (ensinante-aprendente; aprendente-aprendente; ensinante-ensinante; aprendente-ensinante) e são construtores do conhecimento.

Para Saraiva e colaboradores (2006), os novos desafios consistem na incorporação de novas práticas pedagógicas capazes de romper com modelos e cópias voltados para o ensino presencial. Mas, para tal, é necessário sair do estado de acomodação e valorizar a singularidade. Na visão de Santos (2002), o desafio maior está na gestão do processo de EAD. São necessárias, para a autora, novas práticas curriculares coerentes com o espaço de aprendizagem para autorias coletivas.

\subsection{A tutoria Acadêmica no modelo CEDERJ}

O Caderno de Orientação da Tutoria (CEDERJ, 2009) define a atuação do tutor presencial na interface entre o professor coordenador da disciplina, o material didático e o aluno, que conta também com apoio de um ambiente virtual de aprendizagem, com atividades de interação. A mediação junto ao professor coordenador refere-se ao acompanhamento da disciplina, com troca de informações diversas, resolução de dúvidas, orientações quanto ao material didático nos encontros presenciais e outros.

O material didático disponível na plataforma é preparado especificamente para essa finalidade; as informações são ilustradas, possuem linguagem acessível e os conteúdos são elaborados por uma equipe multidisciplinar, com orientações e exercícios para autoavaliação. Logo, o aluno é o centro de todo esse processo, e 
não o material didático, como utilizado, por exemplo, nos cursos por correspondência, vídeos e programas de televisão. Conforme Santos (2002), quando o tutor é alguém que somente repassa informações, o estudante é apenas um receptor; sendo assim, não constrói o conhecimento.

A metodologia da educação a distância proposta no curso em questão busca a formação integral do aluno, transformando-o em sujeito de conhecimento e não em mero receptor. Além das ferramentas disponibilizadas na plataforma, o estudante conta com a ajuda do tutor, que estimula e exercita a visão crítica e a sua participação no processo de aprendizagem.

Esse tutor pode ser presencial ou a distância. A prática do trabalho do tutor envolve vários níveis de atuação. Inicialmente, o papel do tutor é dar apoio ao processo de aprendizagem, no resgate de conhecimentos e experiências. O tutor busca explicitar conteúdos potenciais associados ao conhecimento, emoções e valores do indivíduo. As interferências praticadas pelo tutor conduzem à prática da reflexão. O tutor presencial precisa ter habilidade interpessoal para lidar com o aluno, despertá-lo para compartilhar o conhecimento, provocá-lo para a elaboração própria e estimular, assim, o processo de reflexão num ambiente colaborativo.

A conquista da autonomia pelo estudante, tão necessária na educação a distância, precisa ser trabalhada pelo tutor presencial. Assim sendo, conforme o Caderno de Orientação da Tutoria (CEDERJ, 2009), é necessário, no desempenho de seu papel como orientador de estudo, encontrar caminhos para a solução de problemas os mais diversos. Isso não só desde a promoção da interatividade e a busca de conhecimentos adicionais em grupos de estudo como também no acompanhamento do aluno, especialmente daqueles que não comparecem às tutorias presenciais. $\mathrm{O}$ objetivo é evitar a evasão em educação a distância por falta de apoio acadêmico. O tutor precisa também desenvolver estratégias de acompanhamento, motivando-o e encorajando-o para a ativa participação na construção de sua aprendizagem.

O tutor a distância é um poderoso aliado nesse processo. Suas atribuições são múltiplas. Dentre elas destacam-se o atendimento ao aluno por telefone, numa linha 0800, ou por fax, em horários predefinidos e na sala de tutoria da plataforma. O tutor participa das capacitações dos tutores presenciais, das correções das avaliações presenciais e a distância. Realiza as orientações de monografias ou trabalhos finais de curso. Presta apoio ao professor coordenador da disciplina na oferta de atividades propiciadoras de aprendizagem (fóruns, chats, formação de grupos virtuais e outros), na elaboração de guias de estudo e na revisão do material didático. Trabalha junto ao tutor presencial no atendimento à demanda dos alunos, propiciando interação entre os alunos e apoiando-os no conteúdo específico.

Neste estudo analisaram-se, então, os aspectos formais que caracterizam as atividades do tutor presencial definidas no Caderno de orientação da Tutoria e no projeto político-pedagógico do curso. Os aspectos informais, como as percepções do tutor presencial em relação ao seu próprio trabalho, foram objeto de análise por meio do questionário aplicado e respondido pelos tutores presenciais do Polo de Educação a Distância de Nova Friburgo que atuam no curso de Pedagogia para as séries iniciais. Portanto, não foi analisado aqui o sistema de tutoria a distância. Foram aplicados os questionários aos doze tutores presenciais do polo; a pesquisa alcançou $100 \%$ de respostas.

Quanto à avaliação formal ou processual dos alunos, $73 \%$ dos tutores informaram nunca terem sido consultados pelos coordenadores de disciplinas; os demais $27 \%$ declararam terem sido consultados em fóruns, oficinas e relatórios. Pelas respostas dos tutores, pudemos verificar que as capacitações variam de acordo com cada coordenação de disciplina, assim como o acompanhamento do trabalho do tutor presencial, que é realizado por meio de mensagens na plataforma e encontros presenciais semestrais e/ou anuais. Na opinião de $100 \%$ dos tutores presenciais não foi oferecida capacitação para o uso das mídias, e $84 \%$ dos tutores presenciais declararam que não receberam capacitação em conteúdo, utilizando o material didático específico do curso. Tais capacitações seriam importantes, de modo a potencializar a formação de novas competências, inclusive na área das tecnologias da comunicação. Novamente destaca-se a fragmentação das ações entre as diferentes coordenações de disciplinas, no que se 
refere ao desenvolvimento do trabalho de tutoria.

O questionário também levantou os dados referentes ao perfil dos tutores e as suas opiniões sobre a cultura organizacional, a ambientação $e$ integração $e$ as suas atribuições, mas elas não serão alvo de análise neste trabalho (AUTOR 3, 2010).

\section{Resultados externos}

Uma das formas de verificação da qualidade do curso seria através dos resultados externos que ele produz. A inserção dos egressos no mercado de trabalho e sua atuação profissional seriam também ecos do que foi realizado ao longo do curso de graduação. $\mathrm{O}$ que os ex-alunos estão fazendo? Estão logrando êxito em concursos públicos? Continuaram seus estudos em nível de pós-graduação? Tiveram a sua atuação profissional modificada para melhor?

Nesse sentido, conseguimos recolher, por e-mail $e$ por contato telefônico, as informações de 73 ex-alunas (42,5 \% do total de concluintes) do curso de Pedagogia para as Séries Iniciais do Polo de Nova Friburgo no que se refere à continuação dos estudos e à aprovação em concursos públicos. Pode-se depreender deste levantamento que um número considerável de egressos procurou cursos de pós-graduação, na modalidade presencial ou a distância; obtiveram êxito em concursos públicos realizados pelo estado, pelo município de Nova Friburgo e por municípios vizinhos; e que algumas se sentiram motivadas a retornar ao polo em novo exame vestibular para ingressar no curso de licenciatura em Pedagogia de quatro anos, a fim de obter formação mais ampla do que aquela dos anos iniciais do ensino fundamental. Verificamos também que, no período estudado (agosto de 2003 a maio de 2010), $57,1 \%$ dos discentes do curso de Pedagogia do Polo de Nova Friburgo concluíram com aproveitamento o curso e que a evasão foi de 19,9\% (AUTOR 4, 2010a). $\mathrm{Na}$ opinião desses egressos, o curso possui a qualidade desejada e os capacita a exercer plenamente as suas atividades profissionais e a investir na continuidade de seus estudos.

Outros resultados externos, como os resultados do Enade (Exame Nacional de Desempenho dos Estudantes), poderiam ser citados para avaliar a qualidade do curso, mas, como bem questiona Autor 2 (2010), medir a qualidade do curso pelos resultados de concurso público é uma forma adequada de avaliar a qualidade? Para o autor, "frequentemente a instituição se ufana com os resultados de ex-alunos em provas e concursos" e "os bons e maus resultados nos exames e provas configuram-se como situações pontuais que efetivamente não correspondem à realidade educacional nem à conquista da autonomia acadêmica desejada" (AUTOR 2, 2010, p. 23).

Também a partir das observações de Gatti (2009) e dos dados do Inep (BRASIL, 2009), Waldhelm e Mury (2010) alertam para o fato de que o quantitativo de estudantes formados pode ser considerado ainda pequeno para avaliar a competência dos egressos de cursos em EAD, pois,

mesmo que o curso em Pedagogia na modalidade a distância tenha obtido resultado melhor do que no ensino presencial no Exame Nacional de Desempenho dos Estudantes (Enade) em 2006, é fato que a EAD formou no mesmo ano 25.804 profissionais, enquanto a graduação presencial contabilizou 736.829 (WALDHELM e MURY, 2010, p. 23).

Não há, portanto, opinião unânime sobre como avaliar a qualidade de um curso pelos resultados externos. Nesse sentido, e partindo do pressuposto de que precisamos conhecer o que já foi feito e aprender com as experiências anteriores, defendemos a realização de uma avaliação institucional com o intuito de aprimoramento. Dentre os diferentes tipos de avaliação, a institucional é uma atividade de extrema relevância para a elaboração de ações que possam corrigir deficiências e concentrar esforços na otimização dos pontos positivos. Ela aponta caminhos e certamente tanto melhor será quanto mais ampla for a participação dos atores envolvidos no processo.

Em seu estudo, Gasparetto (2008) faz uma revisão da literatura sobre as diferentes definições, características e princípios de uma avaliação institucional. Com relação à avaliação institucional na universidade, o autor enfatiza que "é um processo sem fim de busca de qualidade do fazer universitário e pressupõe e exige predisposição à mudança" (2008, s/p); e que,

a rigor, uma avaliação institucional stricto sensu sempre será 
uma aproximação, uma pretensão, um desafio e, em última instância, uma utopia. Este fato, todavia, não invalida o esforço de tentar realizá-la. Ao contrário, o propósito é tentar avançar continuamente nessa direção, buscando a superação de situações e de patamares de qualidade do fazer acadêmico. A dimensão do caráter utópico da avaliação institucional reflete a própria natureza da universidade e do seu fazer, reflete a infinita busca da qualidade, da ciência e da tecnologia, todavia, sempre provisórias (GASPARETTO, 2008, s/p).

Sabemos que não há consenso na universidade quanto à importância $e$ à legitimidade das ações $e$ investimentos realizados na EAD. Dessa forma, é urgente a divulgação ampla dos trabalhos desenvolvidos nessa área $e$ a pesquisa e avaliação dos programas e projetos em andamento. Baseados nessa premissa, propomos a realização de uma avaliação institucional enfocando o curso de Pedagogia para as Séries Iniciais no Polo de Nova Friburgo (AUTOR 4, 2010b). Tal proposta advém do fato de tratar-se de um curso em finalização, com ampla gama de dados já disponíveis e que poderia servir de modelo a ser utilizado em estudos avaliativos futuros em outros polos e em outros cursos semipresenciais. Nessa perspectiva, os estudantes dos cursos semipresenciais seriam diretamente beneficiados e a universidade poderia divulgar para as comunidades externa e interna os resultados dos esforços implementados nessa área, dando visibilidade e transparência para as ações realizadas na EAD até o presente momento.

\section{Conclusões}

Concluímos que, apesar de os documentos norteadores do trabalho pedagógico do curso de Pedagogia analisado enfatizarem a necessidade de coesão entre os pressupostos teóricos $e$ as ações no que se refere ao processo avaliativo, ainda há grande dificuldade de vivenciar essa proposta na prática cotidiana. É claro que essa dificuldade não é exclusividade da educação a distância, mas configura-se como um árduo e urgente desafio a ser superado, uma vez que se busca atingir um patamar de qualidade e credibilidade dos cursos oferecidos nessa modalidade. Enfatiza-se ainda que, se o projeto político-pedagógico não é conhecido, considerado, vivido, modificado, discutido, torna-se um re- gistro formal, sem valor.

Dessa forma, os cursos na modalidade EAD precisam envolver os professores (coordenadores e tutores) para que se discutam os problemas que dificultam o aluno no avanço de seu aprendizado, considerando-o como um todo. As ações pensadas, contextualizadas, discutidas e adotadas deverão levar em conta essas dificuldades, objetivando desenvolver um trabalho coeso. Para isso, as avaliações (ADs e APs) devem ser organizadas para promover aprendizagens, propor momentos de estudo (LUCKESI, 2003), além de comprometer-se com a proposta do curso, apresentando estreita relação com o material didático. Somente dessa forma é que se conseguirá modificar também a visão do profissional que está sendo formado, a fim de que ele próprio não reproduza a cultura da prova.

Em relação à tutoria acadêmica, o estudo demonstrou que há necessidade de uma gestão mais estratégica, mediante o alinhamento de ações de capacitação e desenvolvimento de tutores, com políticas mais amplas que envolvam um diagnóstico prévio das necessidades de treinamento, de levantamento de habilidades e competências e dos processos que requeiram mudanças. Percebe-se também a carência de um plano de capacitação de tutores alinhado com o projeto político-pedagógico que fortaleça a cultura organizacional, abrindo a possibilidade de o trabalho do tutor ganhar visibilidade, consistência e credibilidade, de forma mais completa e abrangente, como por exemplo com sua participação efetiva na avaliação processual dos alunos da EAD.

Os dados levantados no curso de Pedagogia oferecido na modalidade semipresencial no Polo de Apoio Presencial de Nova Friburgo apontam para os bons resultados obtidos pelos estudantes e egressos. No entanto, consideramos necessário que se invista na pesquisa de indicadores da qualidade dos cursos de educação a distância e na realização de uma avaliação institucional que seja concebida na dimensão de aprimoramento $e$ transformação, com o envolvimento de todos os atores do projeto de $\mathrm{EAD}$, e que contribua para criar uma cultura de avaliação permanente na universidade.

Sabe-se que a busca por um ensino de excelência, sério, comprometido com a sociedade sempre caracte- 
rizou o projeto político-pedagógico do curso de Pedagogia. E que tal proposta, para legitimar-se, exige contínua reavaliação teórico-prática, apontando lacunas, suscitando divergências e assinalando possíveis soluções. Foi o que se pretendeu com o presente trabalho.

\section{Referências}

AUTOR 1. Uma análise do curso de Pedagogia do Polo EAD de Nova Friburgo: o projeto político-pedagógico. Trabalho final do curso de especialização lato sensu em Planejamento, Implementação e Gestão de EAD, UFF, 2010.

BENTES, Roberto de Fino. A avaliação do tutor. In: LITTO, Fredric Michael; FORMIGA, Manuel M. Maciel (Orgs.). Educação a Distância: o estado da arte. São Paulo: Pearson Education do Brasil, 2009, p. 166-170.

BIELSCHOWSKY, Carlos Eduardo. Educação superior a distância: uma estratégia para avaliação institucional. In: Desafios da educação a distância na formação de professores. Brasília: Ministério da Educação, Secretaria de Educação a Distância, 2006, p.51-65.

BIELSCHOWSKY, Carlos Eduardo e equipe do CEDERJ. Educação a distância na universidade do século XXI. Texto 2 - Cursos de graduação a distância, questões pedagógicas e de gestão, 2003. Disponível em: http://www.redebrasil.tv.br/salto/boletins2003/edu/tetxt2_2.htm. Acesso em 16/06/2009.

BRASIL. Ministério da Educação. Secretaria de Educação a Distância. Referenciais de qualidade para educação superior a distância. Brasília, 2007.

BRASIL. Ministério da Educação. Instituto Nacional de Estudos e Pesquisas Educacionais Anísio Teixeira. Censo da Educação Superior. Brasília: MEC/INEP, 2009. Disponível no site www.ensinosuperior.inep.gov.br.

CEDERJ. Curso de Pedagogia para as séries iniciais do ensino fundamental. Projeto político-pedagógico. Universidade do Estado do Rio de Janeiro, Rio de Janeiro, 2000.

CEDERJ. Caderno de orientação da tutoria. Fundação CECIERJ, Rio de Janeiro, 2009.

$\neg$ FREIRE, Paulo. Pedagogia da autonomia: saberes necessários à prática educativa. São Paulo: Paz \& Terra, 1996.

GASPARETTO, Agenor. Avaliação institucional: processo doloroso de mudança; a experiência da UESC, Ilhéus, Bahia, 2008. Disponível em: www.cappf.org.br/tiki-dowload file.php?fileld=40. Acesso em 03/02/2009.

GATTI, Bernadete; BARRETO, Elba Siqueira de Sá. Professores do Brasil: impasses e desafios. Brasília: Unesco, 2009.

GUSSO, Sandra de F. Krüger. O tutor-professor e a avaliação da aprendizagem no ensino a distância. Ensaios pedagógicos. Revista eletrônica do curso de Pedagogia das Faculdades OPET, 2010. Disponível em www.opet. com.br/revista/pedagogica/artigos. Acesso em 16/05/2010.

AUTOR 4. Uma análise do curso de Pedagogia do Polo EAD de Nova Friburgo: evasão e ações afirmativas. Trabalho final do curso de especialização lato sensu em Planejamento, Implementação e Gestão de EAD, UFF, 2010a.

Avaliação em educação a distância: uma proposta de avaliação institucional. In: BRUNO, Marinilza e RITTO, Antônio (Orgs.). Avaliação em ambientes complexos. Rio de Janeiro: Editora PoD, 2010b, p. 73-94. AUTOR 3. Uma análise do curso de Pedagogia do Polo EAD de Nova Friburgo: o sistema de tutoria. Trabalho final do curso de especialização lato sensu em Planejamento, Implementação e Gestão de EAD, UFF, 2010. LUCKESI, Cipriano Carlos. Avaliação da aprendizagem escolar: estudos e proposições. $15^{\mathrm{a}}$ ed. São Paulo: Cortez, 2003. 
MEDEIROS, Leila et al. Sistemas de tutoria em cursos a distância. Programa Interinstitucional de Capacitação em EAD para a UAB. MEC/SEED, 2007.

AUTOR 2. Uma análise do curso de Pedagogia do Polo EAD de Nova Friburgo: as ferramentas de avaliação. Trabalho final do curso de especialização lato sensu em Planejamento, Implementação e Gestão de EAD, UFF, 2010. MORAN, José Manuel. O que aprendi sobre avaliação em cursos semipresenciais. 2006. Disponível em: www. eca.usp.br/prof/moran. 2006. Acesso em: 15/04/2010.

SANTOS, Edméa Oliveira. Formação de professores e cibercultura: novas práticas curriculares na educação presencial e a distância. Revista da FEEBA, Educação e contemporaneidade, Salvador, v. 11, n. 17, p.113-122, jan/jun 2002.

SARAIVA, Luciana Martins et al. Tensões que afetam os espaços de educação a distância. Psicologia em Estudo, Maringá, v. 11, n. 3, p.483-491, set/dez 2006.

VEIGA, Ilma Passos (Org.). Projeto político-pedagógico da escola: uma construção possível. São Paulo: Papirus, 1995.

WALDHELM, Andrea Paula de Souza; MURY, Rita de Cassia Ximenes. EAD e formação de professores - um estudo experimental no Polo Nova Friburgo. Anais do XV ENDIPE, Encontro Nacional de Didática e Prática de Ensino, Belo Horizonte, 2010. Painel Percepção ambiental, educação a distância e novas tecnologias de comunicação e informação no curso de Pedagogia: contribuições para pensar a formação docente, p. 14-26. 